\title{
Therapeutic effect of the Indigenous drug modality in the management of Adenocarcinoma of colon - A case report based on cytokines expressions
}

\author{
Umayangani LHS, ${ }^{1 *}$ Chandana EPS, ${ }^{2}$ Amarasinghe APG ${ }^{3}$ \\ ${ }^{1}$ Medical officer, Bandaranaike Memorial Ayurvedic Research Institute, Navinna, \\ Maharagama, Sri Lanka. \\ ${ }^{2}$ Deputy vice chancellor, Department of Zoology, Faculty of Science, University of Ruhuna, \\ Sri Lanka. \\ ${ }^{3}$ Senior professor, Institute of Indigenous Medicine, University of Colombo, Sri Lanka.
}

\begin{abstract}
:
A clinical study was conducted from May to July 2017 in the outpatient department of Bandaranaike Memorial Ayurvedic Research Institute (BMARI), Navinna, Sri Lanka to test the antitumor activity of the indigenous drug modality which is used to manage the colon cancer. A forty year old colon cancer patient volunteered to the study. Ethical approval has been taken from the Institute of Indigenous Medicine, University of Colombo Sri Lanka. Detailed history, clinical examinations and relevant investigations were conducted at BMARI and the Department of Zoology, Faculty of Science, University of Ruhuna. Three herbal formulations namely SG powder- $5 \mathrm{~g} /$ day, KY powder $-10 \mathrm{~g} / \mathrm{day}$ and $\mathrm{A} 1$ powder $-10 \mathrm{~g} /$ day were given for the patient throughout 90 days of study. Serum Interleukin-2 (IL-2), Interleukin-5 (IL-5), Interleukin 17 (IL-17), Interferon (IFN)-y and p53 Upregulated Modulator of Apoptosis (PUMA) were quantified using Enzyme-Linked Immunosorbent Assay (ELISA) before and after the treatments (after 45 and 90 days) as these cytokines play a significant role in tumor growth control. Tumor marker expression and stool samples were tested before and after treatments (after 45 and 90 days). Symptoms of colon cancer such as rectal pain were significantly decreased during the treatment. According to the results of the ELISA, IL-2, IFN- $\gamma$ and IL-17 concentrations were increased significantly after the treatment and expression level increased in all three cytokines over time indicating the possible control of colon cancer growth by the drug modality. Further investigations are required to evaluate the mechanism of effectiveness of this indigenous drug modality in controlling Adenocarcinoma of colon.
\end{abstract}

Key words: Adenocarcinoma of colon, Ayurveda, ELISA, Traditional medicine.

Received: 31.05.2021 Revised: 08.06.2021 Accepted: 14.06.2021 Published: 28.06.2021

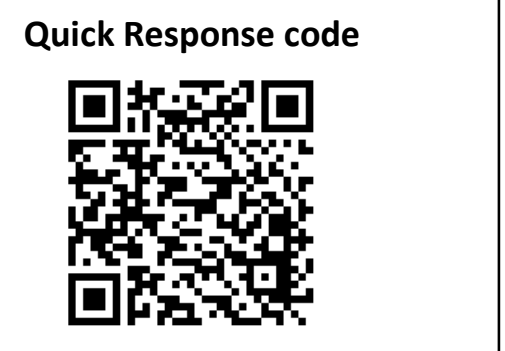

*CORRESPONDING AUTHOR:

Dr. Umayangani LHS

Bandaranaike Memorial Ayurvedic Research

Institute, Navinna, Maharagama, Sri Lanka

E-mail : drlhsumayangani@gmail.com 


\section{Introduction:}

Among non-communicable diseases, cancer places enormous strains on the health care systems throughout the world. Cancer is a major cause of morbidity and mortality, with approximately 14 million new cases and 8 million cancer related deaths in 2012, affecting populations in all countries and all religions. ${ }^{[1]}$ The most commonly diagnosed cancer were the lung (1.82 million), breast (1.67 million) colorectal (1.36 million), and the most common causes of cancer death were lung cancer (1.6 million deaths), liver cancer (74,500 deaths) and stomach cancer (723,000 deaths). ${ }^{[1]}$ Approximately 1,235,108 people are diagnosed and 609,051 died from colorectal carcinoma annually. ${ }^{[2]}$ Colo-rectal carcinoma has various etiological factors include inflammatory bowel disease, dietary factors (high intake of red meat, high intake of fat, increase intake of calcium and low intake of dietary fiber) smoking and alcohol intake. A family history of colorectal cancers or polyps, especially in first-degree relatives is also a strong risk factor. ${ }^{[3]}$

According to the concept of Ayurveda system of medicine, the renowned Ayurvedic authentic texts has named Cancer as Arbuda, Granthi, Apachi, Gandamala and 'Vidradhi. Granthi described as benign or neoplasm and Arbuda described as malignant or major neoplasm. ${ }^{[4-5]}$ Both can be inflammatory or non-inflammatory based on doshas involved. The dosha described as the three principles that regulate the psycho physiological response and pathological changes in the body. The balance of these three doshas (Vata, Pitta and Kapha) in the body, mind and consciousness is the definition of healthiness. ${ }^{[6]}$ Traditional and ancient healthcare systems such as Ayurveda in Asia capable to boosting the immune system and reputed as reliable therapeutic approaches for year. ${ }^{[7]}$ As cancers are rising as a key life-threatening risk in the modern world it became very important to develop effective therapies against cancers.
Although there are several therapies against cancers, the threat is still rising. On the other hand modern cancer treatments such as radiotherapy and chemotherapy can harm healthy cells together with cancer cells causing subsequent health risks. ${ }^{[8]}$ Thus development of natural therapies can benefit most of the world combat against cancers. There are many different defense mechanisms that protect an individual from microorganisms and potentially harmful material. Some of these, including physical barriers like the skin, phagocytic cells and certain chemical substances and enzymes are active before exposure to foreign material. There are two types viz innate or natural immune mechanism and acquired immunity. The innate or natural immune mechanisms are not enhanced by previous exposure to, nor do they discriminate foreign substances. The acquired or adaptive immunity, have components that are able to recognize variation in structures present on foreign material. The defense mechanism is able to eliminate specifically the offending material and, in addition, subsequent exposure leads to a more efficient and effective immune response. ${ }^{[9]}$

Stimulation of immune effector cells and stromal cells at the tumor site and enhancement of tumor cell recognition by cytotoxic effectors cells occurs under influence of several cytokines. Studies on animal tumor models have revealed that cytokines have broad antitumor activity and this has been translated in to number of cytokines-based approaches for cancer therapy. ${ }^{[10]}$ Interleukins are subset of a broader group of cellular messenger molecules which are secreted by immune system cells. Interleukins belongs to a family of immunomodulatory proteins that induce a wide variety of responses in various tissues and organs. [11] Interferons are group of pleiotropic cytokines that play a role in intercellular communication during innate and acquired immune responses and host defense 
against viral and bacterial infections, as well as tumor surveillance. There are two members of Interferon viz type I Interferon (IFN) and type II IFN. IFN-y is the member of type II IFN. ${ }^{[12]}$ p53 Upregulated Modulator of Apoptosis (PUMA) is essential for the apoptosis induced by exogenous or endogenous p53. In addition PUMA (p53 is known to be a key transcriptional target of the tumor suppressor p53 and it carries out cell death cascade in response to $\mathrm{p} 53$ activation. ${ }^{[13]}$ It was found that IL-2 inhibits the tumor growth and induce cell apoptosis. ${ }^{[14]}$ This treatment regimen has never been tested to reveal their biological activity or anti -cancer properties. Scientific knowledge of anti-cancer properties of this drug regimen is essentially important to develop into more efficient and usable formats. The objective of this study was to evaluate the Cytokines expression for the indigenous medical treatment modality in the management of Adenocarcinoma of colon.

\section{Case history:}

A 40 years old married person who works as a navy soldier was referred by the Navy Hospital Complex with the complaints of pain in deification, bleeding with stool and constipation. $\mathrm{He}$ had diagnosed as a moderately differentiate rectal adenocarcinoma in December 2016 by Histopathology report. Magnetic Resonance Imaging (MRI) scan (2017.03.19). report was indicated as a no significant interval change in the size of the lower rectal carcinoma. Tumor infiltration is the mesorectal fascia posterior to the prostate.

This clinical case study was conducted from May 2017 to July 2017 in the outpatient department of Bandaranaike Memorial Ayurvedic Research Institute (BMARI), Navinna. Sri Lanka. Ethical clearance was obtained from the Institute of Indigenous Medicine, University of Colombo, Sri Lanka (ERC No:15/46). The patient was subjected to the clinical study after obtaining his written consent. Detailed history, clinical examinations such as Ashta vidha pariksha relevant were done and Carcinogenic Embronic Antigen (CEA) was tested before and after treatments (after 45 and 90 days). Liver and kidney functions were also investigated such as Serum Glutamic Oxaloacetic Transaminase (SGOT), Serum Glutamic Pyruvic Transaminase (SGPT), Serum creatinine before and after treatment. Interleukin-2 (IL-2), Interleukin-5 (IL-5), Interleukin 17 (IL-17), Gamma Interferon (IFN- $\gamma$ ), p53 Upregulator Modulator Apoptosis (PUMA) were analyzed by quantitative Enzyme-Linked Immunosorbent Assay (ELISA) before and after the treatment at BMARI and the Department of Zoology, Faculty of Science, University of Ruhuna Sri Lanka.

\section{Preparation of drugs:}

The indigenous drug modality was received from Kottayawatta traditional generation. The modality was consisted SG powder, KY powder, A1 powder, and the method of preparation of three drugs are mentioned below.

\section{SG powder:}

Equal amount of the seeds of Piper nigrum, Nigella sativa, Cuminum cyminum Linn, Pimpinella anisum, Trachyspermum roxburghianum, Trigonella foenum-gracum L.), fruit of Piper longum, rhizome of Curcuma longa L, resins of Ferulaasa foetida with same quantity were powdered together.

\section{KY powder:}

The rhizome of Smilax glabra, all parts of Munronia pinnata, seeds of Trachyspermum roxburghianum and resins of Ferulaasa foetida, seeds of Elettraria cardamomum (L.), Piper nigrum, Piper nigrum, Embelia ribes, Hyoscymusniger, with same quantity are powdered all together. Ferulaasa foetida was 
purified by washing with hot water and filtered. Then powder was dried using sunlight.

\section{A1 powder:}

The root stem of Cassia fistula, root of Justicia adhatoda, Operculin aturpethum (L.),

- Fagonia cretica Linn, bark of Tinospora cordifolia, Glyzerryza glabra, fruit of Terminalia chebula, Vitis viniferar Linn, Terminalia bellerica, with same quantity were powdered together.

Three indigenous herbal formulations SG powder, KY powder and A1 powder were given to the patient as shown in the Table1.

Table-1: Administration of indigenous herbal formulations:

\begin{tabular}{|l|l|l|l|l|}
\hline Oral drug & Dosage form & Dose & Drug vehicle & Duration \\
\hline SG powder & Powder & $\begin{array}{l}2.5 \mathrm{~g} \text {-morning Before meal } \\
2.5 \mathrm{~g} \text { - evening Before meal }\end{array}$ & $\begin{array}{l}\text { Black Heenati rice } \\
\text { soup }\end{array}$ & 3 months \\
\hline KY powder & Powder & $\begin{array}{l}5 \mathrm{~g} \text {-morning Before meal } \\
5 \mathrm{~g}-\text { evening Before meal }\end{array}$ & Bee honey & 3 months \\
\hline Al Powder & Powder & $\begin{array}{l}5 \mathrm{~g} \text { - morning Before meal } \\
5 \mathrm{~g} \text { evening Before meal }\end{array}$ & Warm water & 3 months \\
\hline
\end{tabular}

Table-2: Laboratory Parameters assessed:

\begin{tabular}{|l|l|l|l|}
\hline $\begin{array}{l}\text { Laboratory Parameters } \\
\text { assessed }\end{array}$ & Pre- treatment & $\begin{array}{l}\text { After 45 days } \\
\text { treatment }\end{array}$ & $\begin{array}{l}\text { After 90 days } \\
\text { Treatment }\end{array}$ \\
\hline & & & \\
\hline IL-2 concentration $(\mathrm{Pg} / \mathrm{ml})$ & 1669.7 & 1563.2 & 2135.5 \\
\hline IL-5 concentration $(\mathrm{Pg} / \mathrm{ml})$ & 115.3 & 326.2 & 495.1 \\
\hline IL-17 concentration $(\mathrm{Pg} / \mathrm{ml})$ & 61.5 & 491.6 & 994.1 \\
\hline IFN-r Concentration $(\mathrm{Pg} / \mathrm{ml})$ & 76 & 274.7 & 209.1 \\
\hline PUMA concentration $(\mathrm{Pg} / \mathrm{ml})$ & 0.4 & 0.8 & 0.9 \\
\hline CEA & $25 \mathrm{ng} / \mathrm{ml}$ & & $4.54 \mathrm{ng} / \mathrm{ml}$ \\
\hline SGOT levels & $18.1 \mathrm{U} / \mathrm{L}$ & $25.6 \mathrm{U} / \mathrm{L}$ & $18.9 \mathrm{U} / \mathrm{L}$ \\
\hline SGPT levels & $9.4 \mathrm{U} / \mathrm{L}$ & $15.2 \mathrm{U} / \mathrm{L}$ & $15.5 \mathrm{U} / \mathrm{L}$ \\
\hline
\end{tabular}

All treatment regimens were continued for 3 months. During whole course of medication patient was instructed to avoid junk food such as fried food and artificial-instant food, oily food, pork, beef, tuna fish, prawns, cuttlefish, prickle, coffee, chocolate and alcohol.

\section{Serum sample collection and storage:}

Blood samples were collected into an Ethylene diamine tetraacetic acid (EDTA) treated vials. Samples were transported to the laboratory in ice. Samples were centrifuged at 2,000 for 10 minutes at $4{ }^{\circ} \mathrm{C}$. Then serum was separated and aliquoted samples were stored at $-80^{\circ} \mathrm{C}$ until used.

Enzyme-Linked Immunosorbant Assay (ELISA):

IL-2, IL-5, IL-17, (Interferon)-- $\mathrm{\gamma}$, PUMA quantitative ELISA were performed according to product manuals given by the manufacturer (Elabscience Biotechnology Co.Ltd (Elabscience). Evaluation of IL-2, Il-5, IL-17, (Interferon)- $y$ and PUMA quantitative ELISA assay was done before and after treatment. 


\section{Results:}

IL-2 concentration was significantly increased after treatment as shown in Table 02. IL-5 concentration was increased after treatment than pre-treatment. IL-17 concentration was significantly increased after treatment. IFN- $\mathrm{\gamma}$ Concentration was increased after 45 days treatment, but there was slightly decreased after 90 days treatment than 45 days treatment as evident. PUMA concentration was increased after the treatment as shown in Table No.06. SGOT and SGPT levels were decreased after the treatment (Table-2). Clinical symptoms (Pain in deification and melena) were after 90 days. CEA value of the patient was $4.54 \mathrm{ng} / \mathrm{ml}$ after the treatment regimen.

\section{Discussion:}

In the present study IL-2 concentration was significantly increased after the treatment regimen, which may control tumor growth in colon. Another study was shown that IFN-y acts as a rate limiting factor in the development of Adenocarcinoma of colon [15]. In this study, there were significant increased concentration IFN-y after treatment than before treatment that can control development of adenocarcinoma of colon. It was revealed that IL-17 directly or indirectly induces the polarization of tumor tissue infiltration lymphocytes and applies an antitumor effect [16]. In this study IL17 concentration was significantly elevated after the drug modality that promotes to control the adenocarcinoma of colon. It was revealed that PUMA controlled tumour growth by inhibiting cell cycle progression and by stimulating apoptosis [17]. In this study, the concentration of PUMA was increased after treatment. The Indigenous medical treatment could be control survival- and cell deathregulating processes. According to the results of the ELISA, IL-2, IFN- $\gamma$, IL-17 and PUMA concentrations were increased after the treatment and expression level increased in all four cytokines over time indicating the possible control of colon cancer growth by the three drug regimens. In addition Tumor marker was decreased and shown the control of tumour. Liver functions and kidney functions and the symptoms were improved

\section{Conclusion:}

In conclusion, identify an immune network that supports to control the tumor development. In other aspect the experimental evidences are needed in their respective roles of the treatment regimen in antitumor activity and to the Adeno carcinorma of colon. Further studies are required to evaluate and assess the mechanism of effectiveness of this indigenous drug modality in controlling colon cancer.

\section{References:}

1. Jacques F, Isabelle, Rajesh, Sultan E, Colin M, Maris R, Donald M.P, David F, Freddie B, Cancer incidence and mortality worldwide: Source, methods and major patterns in GLOBOCAN 2012, International journal of cancer. 2014

2. Gemma B, Francisco R. M, Alex T, Manuel M.H, Colorectal cancer: from prevention to personalized medicine, 2014, 20(22), p- 6786-6808.

3. Bapsy PP. Clinical Approach to Oncology, Byword Viva Publishers Private Limited, 2004, 10-12.

4. Prof.Sri Kantha Murthy K.R., Susrutha Samhita, Chaukhambha Orientalia, 2001, Vol I(11) 4-23.

5. Singhal GD, Tripathi SN, Sharma KR, Sri Madhavakara Madhavanidana, Sanskrit Text and Madhukosha Commentary With English Translation, Part II, Uttararddha Chapter 40 The Chaukhambha Oriantalia, $1985 \mathrm{p}-234$

6. Aggarwal B B, I chikawa H, Garodia P, Weearasinghe P, Sethi G, Indra D Bhatt, Pandey M K, Shishodia S, Nair M G, Traditional Ayurvedic medicine to modern medicine: identification of therapeutic 
targets for suppression of inflammation and cancer, Oncology, Endocrine \& Metabolic, 2006, 10(1): 87-118.

7. Pandey M.M., Rastogi S, Rawat A.K.S., Indian traditional Ayurvedic system of Medicine and Nutritional supplementation, Evidence - Based Complementary and Alternative Medicine, 2013,12.

8. Donald M. Weir, Stewart J, Immunology, British Library Cataloguing In Publication Data, 1997, Eighth Edition.

9. Lee $\mathrm{S}$ and Margolin $\mathrm{K}$, Cytokines in Cancer Immunotherapy, Cancers, 2011, 13;3(4):3856-3893.

10. Kumar P, Clark M. Clinical Medicine, Elsevier Saunders, 2005, 6: 483-485.

11. Follis A.V,ChipukJE. ,Fisher J C. ,Yun M, Grace C R. , NourseA , Baran Ka, Li Ou, Min L, White S W. ,Green D R. ,and KriwackiR W. , PUMA Binding Induces Partial Unfolding within BCL-xL to Disrupt p53 Binding and Promote Apoptosis, HHS Public Access, 2013, 9(3):163-8.

12. Anestakis D, Petanidis S, Kalyvas S, Nday C M., Tsave O, Kioseoglou Eand Salifoglou A, Mechanisms and Applications of Interleukins in Cancer Immunotherapy, 2015, 16(1): 1691-1710.

13. Zaidi MR, Merlino G. The Two Faces of Interferon- $\gamma$ in Cancer, National library of medicine, 2011, 1; 17(19); 6118-6124.

14. Yu J, Zhang L, Hwang Pl M, Kinzler KW. Vogelstein B, PUMA induces the rapid apoptosis of Colorectl cancer cells, Molecular cell, 2001, 7(3); 673-682.
15. Caporale A, Brescia A, Galati G., Castelli M, Saputo S, TerrenatoI, CucunaA, Liverani, Gasparrini A M, Ciardi A, Scarpini M, Cosenza U.M., Locoregional IL-2 therapy in the treatment of Colon cancer. Cell induced lesion of Murine model, Anticancer research 2007, 27: 985990.

16. Wang Lu, Wang Y, Zhiyu S, Jiahui C, and XianjunQ, Deficiency of InterferonGamma or Its Receptor Promotes Colorectal Cancer Development Journal of Interferon \& Cytokine Research. 2015, 35(4): 273-280.

17. Yang L, Liu H, Zhang L, Hu J, Chen H , Wang L, Yin X, Li Q , and Qi Y, Effect of IL-17 in the development of colon cancer in mice, Oncology letters, 2016,12(6); 4929-4936.

Conflict of interest: Author declares that there is no conflict of interest.

Guarantor: Corresponding author is guarantor of this article and its contents.

\section{Source of support: None}

\section{How to cite this article:}

Umayangani LHS, Chandana EPS, Amarasinghe APG. Therapeutic effect of the Indigenous drug modality in the management of Adenocarcinoma of colon - A case report based on cytokines expressions. Int. J. AYUSH CaRe. 2021; 5(2):107-112. 